\title{
EUTOMIA
}

Revista de Literatura e Linguística

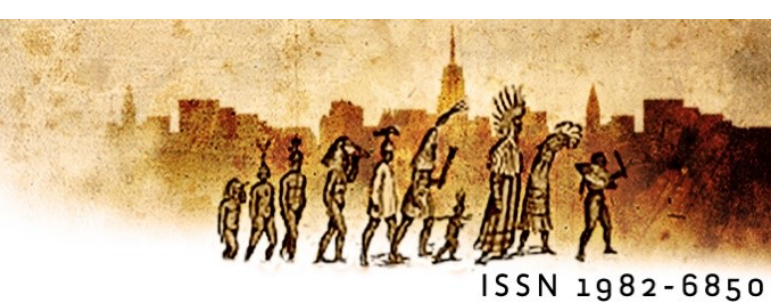

\section{Perspectivas ontológicas e éticas da (inter)subjetividade}

\author{
Ricardo Lima Gomes ' (UFPE) \\ Maria Cristina Hennes Sampaio ii (UFPE)
}

\begin{abstract}
Resumo:
O presente ensaio tem por objetivo investigar os questionamentos filosóficos acerca da noção de (inter)subjetividade. Para esse fim procedeu-se a uma análise dialógica do pensamento de três importantes filósofos dos séculos XIX e XX, respectivamente: Soren Kierkegaard, Mikhail Bakhtin, Martin Heidegger. Enquanto o primeiro parte da distinção entre objetivo e subjetivo, para defender uma radicalização do pensamento subjetivo, Heidegger e Bakhtin enfatizam a coexistencialidade do homem e a responsabilidade ontológica. Para Heidegger (2005), as estruturas originárias do Dasein são o ser-no-mundo, o ser-com e a co-pre-sença - o que nos permite concluir que antes da própria pre-sença, os outros já estariam co-pre-sentes no ser-no-mundo -, ou seja, o ser-com-o-outro, determina existencialmente o Dasein. Quanto a Bakhtin (2016), são nos momentos comuns de uma arquitetônica, constituída por um conjunto de mundos concretamente individuais, que reside a (inter)subjet ividade, ou seja, as várias arquitetônicas concretas são a ponte ontológica da ética individual bakhiniana.
\end{abstract}

Palavras-chave: Intersubjetividade; Ontología; Ética; Discurso.

\begin{abstract}
:
The present essay aims to investigate the philosophical questions about the notion of (inter)subjectivity. For this purpose a dialogical analysis of the thought of three important philosophers of the nineteenth and twentieth centuries, respectively: Soren Kierkegaard, Mikhail Bakhtin, Martin Heidegger has been conducted. While the first considers the distinction between objective and subjective, to defend a radicalization of subjective thinking, Heidegger and Bakht in emphasize the coexistentiality of man and the ontological responsibility. For Heidegger (2005), the originat ing structures of Dasein are the being-in-the-world, the being-with and the co-presence, which allows us to conclude that before the pre-sence itself, the others would be already present in the being-in-the-world; that means, the being-with-the-other, determines, existentially, the Dasein. As
\end{abstract}


for Bakhtin (2016), it is in the common moments of an architectonic, constituted by a set of concretely individual worlds, that resides the (inter)subjectivity, that is, the various concrete architectures are the ontological bridge of the individual bakhinian ethics.

Keywords: (Inter)subjectivity; Ontology; Ethics; Discourse.

\section{Introdução}

O presente ensaio tem por objetivo investigar os questionamentos filosóficos acerca da (inter)subjetividade. Nossas fontes filosóficas são o russo o dinamarquês Soren Kierkegaard (1813-1855), Mikhail Bakhtin (1895-1975) e o alemão Mart in Heidegger (18891976). Para esse fim, procedemos a uma análise dialógica do pensamento desses três filósofos nas obras: Pós-escritos às migalhas filosóficas (1846-2013), Para uma filosofia do ato ético (1924-2016) e Ser eTempo (1927-2005), respectivamente. Apesar de não haver uma referenciação direta entre os referidos pensadores, todos eles parecem contestar o que Kierkegaard (2013) chamou de pensamento objetivo, Bakhtin (2016) de teoreticismo e Heidegger (2005) de esquecimento do ser. Nesse contexto, cabe lembrar que a reação ao positivismo, no início do século $\mathrm{XX}$, fora liderada pelo filósofo e matemático alemão Edmmund Husserl (2012) no contexto do que ele chamou de crise das ciências e do pensamento europeu. Assim, o filósofo (HUSSERL, 2012), partindo da noção kantiana de sujeito transcendental, inaugurou uma nova forma de abordagem dos fenômenos: a fenomenologia transcendental. Não obstante, diferentemente de Husserl (2012), Kierkegaard (2013), Bakht in (2016) e Heidegger (2005), ao se contraporem ao positivismo, parecem estar mirando mais o idealismo alemão de Hegel e, de certa forma, o racionalismo francês de Descartes. Kierkegaard (2013), no entanto, parte da dist inção entre objetivo e subjetivo de Descartes, para defender uma radicalização do pensamento subjetivo. Assim, destaca a importância da fé e da paixão para a existência humana e aponta que a verdade é um processo interno e subjetivo, resultante do paradoxo entre a certeza e a dúvida. $\mathrm{A}$ filosofia kierkegaardiana, apesar de estar envolta em um forte discurso teológico e cristão, tem significativa importância para a noção do pensamento subjetivo, em contraposição a um sujeito abstrato de Hegel e à ética transcendental kantiana. Kierkegaard (2013) defende que o maior princípio ético humano é o tornar-se subjetivo. Entretanto, o filósofo parece não avançar muito em relação à noção de intersubjetividade, conceito que não aparece na obra estudada. A conexão inter-humana, para ele, reside na fé cristã, sobretudo, na paixão, 
na esperança e na incerteza da imortalidade.

No que toca à fenomenologia transcendental, esta parece ser a ponte entre o pensamento subjet ivo de Kierkegaard (2013) e as ontologias de Bakht in (2016) e Heidegger (2005). Husserl (2012) diferentemente de Kierkegaard (2013), prescinde do debate teológico. Não obstante, questiona também a chamada verdade científica objetiva e a divisão conceitual objetividade/subjetividade (HUSSERL, 2012). Quanto a Bakhtin (2016) e Heidegger (2005), ambos realizam uma verdadeira virada ontológica na fenomenologia husserliana ao trazerem, respectivamente, para o centro de suas reflexões, a questão do ser, em seu acontecimento e facticidade. Embora Bakhtin (2016) e Heidegger (2005) não assumam a dicotomia entre subjetivo e objetivo, suas ontologias guardam ressonância com a noção de subjetividade kierkegaardiana.

\section{Fé, vontade e disposição}

O subjetivismo radical de Kierkegaard (2013) certamente foi um ponto de apoio, direto ou indireto, para o movimento antirracionalista de Bakhtin (2016) e Heidegger (2005). Já a subjetividade, para Husserl (2012), era fundamentalmente racional, ainda que o filósofo pleiteasse o retorno ao mundo vivido. Apesar do reconhecimento da importância da fenomenologia husserliana, o pensamento de Bakhtin (2016) e Heidegger (2005) é influenciado pela noção de subjet ividade do filósofo de Copenhague. Kierkegaard (2013) ao falar sobre a fé, como elemento central da subjetividade, sugere que o interesse pessoal e infinito é muito mais forte do que a cabeça de muitos eruditos: "Se o assunto é tratado objet ivamente, o sujeito não pode relacionar-se apaixonadamente com a decisão; e, menos ainda, estar apaixonadamente, infinitamente interessado" (KIERKEGAARD, 2013 p. 37). Para o filósofo (KIERKEGAARD, 2013), o maior princípio ético humano é o tornar-se subjetivo, sendo a ética e a verdade consideradas como um processo interno. Kierkegaard (2013) apoia-se no cristianismo em sua luta contra o pensamento objetivo e resiste às tentat ivas das correntes teológicas em demonstrar objet ivamente a verdade da fé cristã:

Assim o cristianismo protesta contra toda objetividade; quer que o sujeito se preocupe infinitamente consigo mesmo. Aquilo pelo que ele pergunta é a subjetividade; só nela se encontrará a verdade do cristianismo, se é que ela aí estará; objetivamente, ela simplesmente não existe (KIERKEGAARD, 2013, p. 134). 
Quanto a Heidegger (2005), o filósofo parece prescindir do debate teológico para a construção de sua ontologia. Já Bakht in (2016), embora na introdução de Para uma filosofia do ato, ele apresente, como quarto e último ponto de seu projeto de trabalho, a religião, o filósofo não deu continuidade às reflexões sobre o tema. Não obstante, para o presente estudo, a questão mais importante, no pensamento de Kierkegaard (2013), não é a religião, mas a ênfase de seu pensamento aos elementos não-racionais na const ituição do sujeito e de como esse sujeito é um sujeito único, impossível de ser reduzido à uma abstração transcendental. Nesse aspecto, parece-nos que Bakhtin (2016) e Heidegger (2005) aproximam-se do pensamento kierkegaardiano. Retomando o pensamento filosófico de Bakht in (2016) cabe ressaltar que, para ele, o tom emocional-volitivo é parte fundamental do acontecimento do ser" $^{2}$ " $O$ real pensamento que age é um pensar emocional-volitivo, um pensar que entona, e essa entonação impregna de uma maneira essencial todos os momentos do conteúdo de um pensamento" (BAKHTIN, 2016, p. 51-52). Assim sendo, o pensamento científico e a razão teórica seriam apenas momentos desse sujeito, ou do acontecimento do ser. Senão vejamos:

O mundo como o conteúdo do pensamento científico é um mundo particular: é um mundo autônomo, mas não um mundo separado; é antes um mundo que se incorpora no evento unitário e único do ser através da mediação de uma consciência responsável, em uma ação real. Mas o evento único do ser não é mais algo que é pensado, mas algo que é (...) realmente experimentado, afirmado de uma maneira emocional-volitiva, e a cognição constitui apenas um momento desse experimentar-afirmar (BAKHTIN, 2016, p. 30-31).

Já Heidegger (2005), poucas vezes refere-se a sujeito, sendo o conceito Dasein (ou Ser-aí) o que mais se aproxima dessa noção. Assim como Kierkegaard (2013) e Bakhtin (2016), elementos considerados como não-racionais terão grande importância na constituição do Dasein. Dentre esses destacam-se: o humor, a disposição, o temor e a angústia. Heidegger (2005) não trata o humor apenas como um estado da alma, mas como algo que conduz ao ser do Dasein. Para ele, o humor é a própria abertura do ser do Dasein em seu fato. O caráter ontológico da disposição abre o Dasein, em seu estar-lançado no

\footnotetext{
${ }^{1}$ Para facilitar o estudo e a aproximação dessa noção entre Bakht in e Heidegger, optamos pela tradução dessa expressão, do russo-para o espanhol, de Tatina Bubnova, em Hacia una filosofia del acto ético. De los borradores e otros escritos (BAJTIN, 1997), como acontecimento do ser ao invés de ser-evento, contida na tradução de Por uma filosofia do ato ético, de Faraco e Tezza (BAKHTIN, 2016).
} 
mundo, ao caráter essencial da disposição. Trata-se, pois, de um modo existencial básico do Dasein. Esses entendimentos sinalizam para uma aproximação do pensamento de Heidegger (2005), Bakht in (2016) e Kierkegaard (2013) quanto a valorização de elementos subjetivos, considerados como não-racionais, tais como a afetividade, a vontade e os sentimentos:

No entanto, não se atenta para o fato de que a interpretação ontológica fundamental dos afetos, desde Aristóteles, não conseguiu dar nenhum passo significativo. Ao contrário, os afetos e sentimentos passaram a figurar tematicamente entre os fenômenos psíquicos para, ao lado da representação e da vontade, formar a terceira classe. Eles se rebaixaram a fenômenos subsidiários (HEIDEGGER, 2005, p. 193).

\section{Superação da distinção entre subjetivo - objetivo e o questionamento da própria noção de sujeito}

Kierkegaard (2013) em seu processo de radicalização da subjetividade e de luta contra o pensamento objetivo, de certa maneira, reforça e amplia a dicotomia entre sujeito e objeto, talhada pela filosofia moderna desde Descartes (apud DYNNIK, 1968). Já o movimento empreendido por Heidegger (2005) e Bakhtin (2016), embora tivessem preocupações semelhantes às de Kierkegaard (2013), parecem apontar para um caminho diferente. Por vias distintas, Bakhtin (2016), pelo ato ético, e Heidegger (2005), pela ontologia, chegarão a conclusões deveras congruentes.

Heidegger (2005) questionando o cogito sum, de Descartes, indica que a contribuição dos racionalistas deu-se apenas por trazerem a reflexão filosófica para uma região privilegiada do ser, mas que, ao se concentrarem no método de conhecimento, esqueceram-se da questão primeira: de questionar o ser capaz de conhecer. Heidegger (2005, p.82; 84), então, sinaliza para uma compreensão mais originária do ser, que prescinde dos termos sujeito e eu que, segundo ele, deturpariam o fenômeno do Dasein:

Além disso, o ser da pessoa não pode exaurir-se em ser um sujeito de atos racionais, regidos por determinadas leis. [...] Uma das primeiras tarefas da analítica será, pois, que o princípio de um eu e sujeito, dados como ponto de partida, deturpa, de modo fundamental, o fenômeno da pre-sença [Dasein] (HEIDEGGER, 2005, p. 84; p. 82).

Bakhtin (2016), por sua vez, embora utilize de maneira recorrente o termo sujeito, utiliza-se, de maneira original, da expressão acontecimento do ser, voltando, sua filosofia moral, não centralmente para o ser, como Heidegger (2005), mas para o ato do ser, através 
do qual procurará interpretar suas condições e implicações. Não obstante, veremos que a questão ét ica bakht iniana também irá pautar-se por reflexões ontológicas semelhantes.

\subsection{A filosofia moral de Bakhtin e o acontecimento do ser}

Para Bakhtin (2016), tanto as atividades estéticas como o pensamento discursivo teórico cindem determinado ato de sua respectiva significação. Nesse sentido, o projeto filosófico bakht iniano visa reestabelecer essa unidade. Para ele, a crise filosófica do início do século XX devia-se à incapacidade em se realizar a unidade entre o mundo da cultura e o mundo da vida, considerando que todos os esforços racionais, incluindo-se aí, a fenomenologia, não teriam dado conta de realizar tal tarefa. A nosso ver o esforço de Bakhtin (2016), concentra-se, inicialmente, em superar a dicotomia entre subjetivo e objetivo, entre o pensar e o agir, conforme já observado por Bocharov (2016): "Bakht in desenvolve uma crítica ao 'teoreticismo fatal' da filosofia daquele tempo (na epistemologia, na ética e na estética) e opõe a ele, como uma tarefa a ser realizada, a 'unidade responsável' do pensamento e da ação realizada." Para Bakht in (2016), o elemento objetivo (conteúdo-sentido) e o subjetivo (histórico-individual) seriam, na verdade, momentos de um mesmo ato executado:

Como um ato executado, um dado pensamento forma um todo integral: tanto seu conteúdo-sentido quanto o fato de sua presença, na minha consciência real [...] ambos os momentos (o momento do conteúdosentido e o momento histórico-individual) são unitários e indivisíveis na avaliação desse pensamento como minha ação ou ato responsável (BAKHTIN, 2016, p. 21).

A própria noção bakhtiniana de ato possui um significado que transpassa a dicotomia objetivo-subjetivo: "cada pensamento meu, junto com o seu conteúdo, é um ato ou ação que realizo" (BAKHTIN, 2016, p.21). É possível observar que, para o filósofo russo, não há uma dist inção entre o pensar e o agir, já que, para ele (BAKHTIN, 2016), nem toda a ação é capaz de circunscrever o significado e o vivido. É nessa discussão do ato, de sua qualidade, que inicia-se a reflexão ética bakhtiniana, inseparável de uma reflexão ontológica. Em uma das passagens mais importantes da obra, Bakhtin (2016), para discutir o ato, utiliza-se da alegoria do Jano bifronte, divindade romana responsável pelas transições, pelos inícios e fins, cujas duas faces, voltadas para direções opostas, representam, também, o passado e o futuro. Por ser demasiado extensa, apresentaremos a 
citação em duas partes:

Um ato de nossa atividade, de nossa real experiência é como um Jano bifronte. Ele olha em duas direções opostas: ele olha para a unidade objetiva de um domínio da cultura e para a unidade irrepetível da vida realmente vivida e experimentada. Mas não há um plano unitário e único onde ambas as faces poderiam mutuamente se determinar com relação a uma única e singular unidade. É apenas o evento único do Ser [acontecimento do ser] no processo de realização que pode const ituir essa unidade única; tudo que é teórico ou estético deve ser determinado como um momento constituinte do evento único do Ser, embora não mais, é claro, em termos teóricos ou estéticos (BAKHTIN, 2016, p. 20).

Na citação acima o filósofo faz uma reflexão acerca do ato cindido que, como um Jano bifronte, olha em direções opostas sem que haja um plano unitário capaz de Ihe garantir uma unidade singular. Esse ato seria o ato meramente estético, ou meramente teórico. Bakht in (2016) delimita, então, a região ontológica, onde é possível const ituir essa unidade: a do acontecimento único do ser, na vida de fato vivida. Portanto, tudo o que é teórico, tudo o que é estético seriam momentos constituintes desse acontecimento. Os elementos objetivos só poderiam ocorrer fora do ser, como seus duplos, destituídos de vida. Na citação abaixo, o filósofo prossegue seu pensamento acerca do ato:

Um ato deve adquirir um plano unitário singular para ser capaz de refletirse em ambas as direções - no seu sentido ou seu significado e em seu ser; ele deve adquirir a unidade de dupla responsabilidade - tanto pelo seu conteúdo (responsabilidade especial) como pelo seu Ser (responsabilidade moral). E a responsabilidade especial, além disso, deve ser trazida (deve entrar) em comunhão com a responsabilidade moral única e unitária como um momento constituinte dela. Esse é o único meio pelo qual a perniciosa divisão e não-interpenetração entre cultura e vida poderia ser superada (BAKHTIN, 2016, p. 20).

Além do ato ser resultado do acontecimento do ser, e não de um sujeito abstrato e transcendental, ele deve ter uma dupla responsabilidade: com seu conteúdo e com o seu ser, a responsabilidade especial é um momento constituinte da responsabilidade moral, que é a principal. Para tanto, Bakhtin (2016) utiliza o termo postupok, traduzido para o português, como ato ético responsável. O ato ético é executado pelo ser no próprio ser. Observa-se, assim, que a reflexão bakhtiniana é ética e também ontológica. Tudo o que é considerado objetivo, pelo racionalismo, toda significação especializada, na visão bakhtiniana, são momentos constituintes do acontecimento do ser: somente através do ato responsável pode-se não expulsar essa objetividade de dentro da subjetividade 
individual: "Mas do ato executado (não da sua transcrição teórica) há um caminho para o seu conteúdo-sentido, que é recebido e incluído do interior daquele ato realmente executado; porque o ato é realmente executado no Ser." (BAKHTIN, 2016, p. 30) Ou seja, o ato ético é o caminho para incluir o conteúdo-significado dentro do próprio ato, o que significa incluir o conteúdo-significado dentro do próprio ser, pois o ato ético acontece no ser.

Mas o que representa a ét ica para Bakht in? O filósofo russo, de imediato, irá recusar a ética formal de Kant, que estabelece o dever com uma categoria da consciência teórica: para ele, ao contrário, o dever é:

(...) precisamente a categoria do ato individual; ainda mais do que isso - é uma categoria da individualidade, da unicidade de um ato realizado, de sua compulsoriedade única, de sua historicidade, da impossibilidade de trocálo por nada ou lhe fornecer um subst ituto (BAKHTIN, 2016, p. 43).

Observa-se, pois, que a reflexão acerca do dever insere-se na discussão do ato executado. Enquanto o dever kantiano (BAKHTIN, 2016), é um a priori teórico, um conteúdo-significado, para Bakhtin (2016), é um ato cindido, porque não parte da vida realmente vivida e existe de maneira objetivamente abstrata, fora do acontecimento do ser. Da mesma maneira, o pensador russo insurge-se contra o imperativo categórico do iluminista alemão, que determina o ato realizado com uma lei universalmente válida (BAKHTIN, 2016); mas isso seria a pura legalidade, objetiva e abstrata, cindida da vida de fato vivida. O ato ético responsável (postupok), por sua vez, é o dever-ser resultante da responsabilidade do ser; o imperativo categórico serviria apenas de um álibi para a ação do ser, sendo o postupok justamente o não-álibi. A reflexão ét ica de Bakhtin (2016) é, portanto, profundamente ontológica, pois na execução do ato responsável o que está em jogo é o próprio ser.

\subsection{A ontologia da facticidade de Heidegger e o Dasein}

Em Heidegger (2005), como veremos adiante, a questão ética do ato, de sua responsabilidade, também é tratada, mas o centro de suas atenções está voltada para o problema ontológico. Se Bakht in (2016) levanta a filosofia moral como filosofia primeira, Heidegger (2005) sustenta que, para ele, a filosofia é uma ontologia fenomenológica e universal. Claro que não seria justo ou correto ladear um manuscrito incompleto a uma obra 
acabada, como Ser e Tempo. O que queremos, apenas, é destacar que, por caminhos distintos, Bakhtin (2016) e Heidegger (2005), partindo de uma mesma origen, a fenomenologia, chegarão a conclusões congruentes, sendo que o filósofo alemão, ao longo de sua vida, continuará dedicando-se às questões filosóficas propriamente ditas, e o pensador russo concentrará seus estudos na linguagem e na literatura. No entanto, as bases comuns de seus pensamentos apontam para uma possível aproximação da teoria dialógica, de Bakhtin (2016), com a ontologia de Heidegger (2005). Veremos, também, como a abordagem heideggeriana ultrapassa a dicotomia subjetivo-objetivo ao colocar, no centro de sua reflexão, a questão do ser.

Na obra Ser e Tempo, Heidegger (2005) busca at ingir dois objetivos ontológicos: a retomada da questão do ser, como problema principal da filosofia, e, a partir dessa, a interpretação do sentido do ser. Ao defender a primazia do ser, em concordância com Platão e Aristóteles, ele destaca que a questão do sentido do ser não fora abordada pelos filósofos clássicos, os quais julgavam impossível defini-la. Mas essa certa impossibilidade de definição do que é o ser, não deve impedir a investigação ontológica: "ao contrário, justamente por isso a exige" (HEIDEGGER, 2005, p. 29).

Segundo Heidegger (2005), a estrutura formal de seu questionamento do ser consiste em: o interrogado é o ente; o questionado é o ser; e o perguntado é o sentido do ser. Sendo assim, pode-se definir ente e ser: "Ente é tudo de que falamos, tudo que entendemos (...); ente é também o que e o como nós mesmos somos. Ser está naquilo que é e como é, na realidade, no ser simplesmente dado, (...) na pre-sença, no 'há'." (HEIDEGGER, 2005, p. 32). O ser é sempre o ser de um ente (HEIDEGGER, 2005), mas o ser não se comporta como outro ente e nem existe um ser por detrás de outro ser.

Mas, dentre os entes existentes, haveria algum pelo qual o questionamento, pelo sent ido do ser, deveria iniciar-se? Para Heidegger (2005), esse ente é o Dasein (Ser-aí), pois esse é o único ente que possui, em seu ser, a capacidade de questionar. Na ontologia tradicional, o ser exist ia como um pressuposto, como um conceito fora das coisas. O ser que Heidegger (2005) procura pertence à consituição essencial do próprio Dasein, a existência é o ser do Dasein. Ou seja, é na existência concreta do Dasein que o seu ser estabelece uma relação com seu próprio ser. Assim como Bakhtin (2016), Heidegger (2005) desconstrói a dicotomia objetivo e subjetivo, modificando a noção moderna de subjetividade:

Esta ideia de subjetividade é desconstruída por Heidegger na referência à 
hermenêutica da duplicidade (ser/ente), que indicia a forma pela qual o seraí mundano significa, tanto em seu contexto fenomenológico como em seu caráter de encontrar-se no mundo (SAMPAIO, 2016, p. 3).

A obra Ser e Tempo constitui o esforço de Heidegger (2005), em sua investigação do sentido do ser em geral, a part ir da compreensão das estruturas ontológicas do Dasein. 0 filósofo, após extenuantes repetições analíticas, demonstra que o tempo constitui o sentido do ser. Mas essa questão foge ao escopo de nosso estudo. Interessa-nos, sobremaneira, as conclusões heideggerianas sobre as estruturas ontológicas do Dasein e a relação do ser deste com o ser em geral.

Dessa última questão, isto é, da relação entre a investigação do Dasein e dos seres, em geral, reside uma importante questão epistemológica. Para Heidegger (2005), a partir da elucidação do sentido do ser do Dasein, isto é, da existência humana, cria-se as condições filosóficas para o desvelamento do ser de todos os outros entes. Não como uma resposta apriorística, mas como o desenvolvimento de uma fenomenologia hermenêutica capaz de dar abertura ao acontecimento do ser.

Na medida, porém, em que se desvendam o sentido do ser e as estruturas fundamentais da pre-sença [Dasein], em geral, abre-se o horizonte para qualquer invest igação ontológica ulterior dos entes não dotados do caráter da pre-sença. A hermenêutica da pre-sença torna-se também uma 'hermenêutica' no sentido de elaboração das condições de possibilidade de toda invest igação ontológica. (HEIDEGGER, 2005,p. 68-69).

Aqui avaliamos que há um ponto em comum entre os pensamentos de Heidegger (2005), Kierkgaard (2013) e Bakhtin (2016). Embora, Heidegger (2005) não fale em pensamento subjetivo, ao colocar que a análise existencial do Dasein ele abre o horizonte para futuros estudos, indicando sua importância para a investigação da própria subjet ividade, da vida realmente vivida, da existência do ser, como elemento fundamental em uma teoria do conhecimento. Afinal, para o filósofo alemão, o conhecer é um modo de ser do Dasein. A invest igação do próprio ser, o autoquest ionamento do sujeito, é o início de qualquer investigação. Para Heidegger (2005), entretanto, o problema inicia-se justamente no modo de interrogar e revelar o Dasein e suas estruturas ontológicas.

Na verdade, Heidegger (2005) traça uma distinção conceitual que percorre sua obra do início ao fim, não na dicotomia clássica ser versus ente, mas sim entre os entes com o modo de ser do Dasein e os seres simplesmente dados. O ser, do Dasein, é a sua existência, 
enquanto o ser dos outros entes é a sua essência.

A 'essência' da pre-sença está em sua existência. As características que se podem extrair deste ente não são, portanto, 'propriedades' simplesmente dadas de um ente simplesmente dado que possui esta ou aquela 'configuração'. As características constitutivas da pre-sença são sempre modos possíveis de ser e somente isso. Toda modalidade de ser deste ente é primordialmente ser. Por isso, o termo 'pre-sença', reservado para designa-lo, não exprime a sua quididade como mesa, casa, árvore, mas sim o ser (HEIDEGGER, 2005, p. 77-78).

Segundo Heidegger (2005), o problema de toda a filosofia foi procurar interpretar o Dasein como se este fosse igual ou da mesma qualidade que os entes que vem ao nosso encontro no mundo: "A antiga ontologia ret irava dos entes, que vêm ao encontro dentro do mundo, a base exemplar de sua interpretação do ser" (HEIDEGGER, 2005, p. 80). Esse tipo de compreensão é a forma espontânea do entendimento próprio do Dasein, que procura compreender-se a partir da luz que emana do mundo, a part ir do entendimento dos entes que Ihe vem ao encontro. O que Heidegger (2005) propõe é o oposto: só é possível compreender ontologicamente os entes intramundanos através da compreensão das estruturas ontológicas do Dasein. Estes entes, desprovidos do modo de ser do Dasein, são chamados de instrumentos, e o seu o modo de ser, a sua essência, de manualidade. Nesse sentido, o Dasein estabelece uma relação ontológica com o instrumento, uma relação com sua manualidade e não com o seu comprimento ou a sua largura. No entanto, o instrumento só revela sua manualidade na relação com o Dasein: ele só existe ontologicamente no Dasein. Heidegger (2005) oferece-nos um exemplo bem concreto, ao relacionar, os instrumentos, com o modo de ser referencial: a seta automotiva, a ação de mostrar desse ente, assim como o martelar de um martelo, não pertencem a eles, mas ao Dasein que os manuseia. Esse é apenas um de vários exemplos de como Heidegger (2005) supera a dicotomia entre subjet ivo e objet ivo. A seguir, analisaremos como a relação do Dasein com outros Daseins é diferenciada, quando comparada aos entes intramundanos.

\section{O que são, então, o mundo, as coisas e os outros para o ser?}

Tanto a filosofia ética de Bakhtin (2016) como a ontologia de Heidegger (2005) nos colocam um mesmo desafio: o de como escapar de um individualismo absoluto e tratar a alteridade. Bakht in (2016), ao reagir contra o imperat ivo categórico de Kant e propor uma 
ética fundada exclusivamente na responsabilidade do ser, avança num sentido que aparentemente nega a alteridade, numa espécie de solipsismo. Afinal, se apenas eu sou o irradiador dos critérios morais de minha at itude, como o outro poderia interferir, ou mesmo constituir, as minhas ações? Tomemos a seguinte citação e reflitamos como dela pôde constituir-se o dialogismo bakht iniano:

Eu também participo no Ser de uma maneira única e irrepetível: eu ocupo um lugar no Ser único e irrepetível, um lugar que não pode ser tomado por ninguém mais e que é impenetrável a qualquer outra pessoa. No dado ponto único onde eu agora estou, ninguém jamais esteve no tempo único e no espaço único do Ser único. E é em torno deste ponto único que todo o Ser único se dispõe de um modo único e irrepetível. Aquilo que pode ser feito por mim não pode nunca ser feito por ninguém mais. $A$ unicidade ou singularidade do Ser presente é forçadamente obrigatória (BAKHTIN, 2016, p. 58).

Por sua vez, na fenomenologia heideggeriana, centrada na discussão ontológica do Dasein e de suas estruturas, o que seriam os outros Daseins? Seriam apenas momentos ou modos de ser de um Dasein próprio e singular? Seriam entes intramundanos, dotados do modo de ser do Dasein que, assim como os instrumentos, vêm ao encontro de um único Dasein, que seria uma espécie de sol diante do qual todo o sistema de seres gravita? $\mathrm{Na}$ verdade, ao romperem a dist inção entre objetivo e subjetivo e reduzirem tudo a momentos e modos do acontecimento do ser ou do Dasein, inevitavelmente Bakhtin (2016) e Heidegger (2005) colocam-se diante do enigma de como escapar do solipsismo. No século XVII, o filósofo inglês Berkley (apud DYNNIK, 1968) questiona a concepção materialista de um mundo objetivo, independente da percepção subjetiva do ser humano. Para ele, essa concepção era um pré-conceito metafísico, vibrações de um único ser. Quanto a materia, esta existiria apenas como parte das nossas sensações e os humanos existiram como exatamente no ponto de que, se tudo são sensações do ser, seria possível que os outros seres fossem apenas sensações de um indivíduo único. Isto, de nosso ponto de vista, constitui-se um solipsismo, um contrassenso filosófico difícil de ser sustentado. Evidentemente, Heidegger (2005) e Bakhtin (2016) antecipam-se a essas críticas, procurando construir um pensamento que, ao indiferenciar o subjet ivo do objetivo, escape do labirinto solipsista.

\subsection{A arquitetura do mundo real do ato responsável de Bakhtin}


A ontologia bakht iniana, isto é, suas reflexões acerca do acontecimento único do ser, não recaem em um idealismo subjetivo. Para Bakhtin (2016, p. 63) "há tantos mundos diferentes do evento quantos centros individuais de responsabilidade, isto é, eus (selves) participativos únicos (não indiferentes), e seu número é vasto." Sua ética, entretanto, apesar de nos livrar do peso do imperativo categórico e nos dar a liberdade total do arbítrio, poderia conduzir-nos ao um relativismo absoluto, a uma falsa noção da comunidade de seres como um arquipélago sem oceano. Afinal, se ninguém pode jamais estar onde eu estou, como poderia julgar os meus atos? Bakhtin (2016, p. 71) parece resolver esse paradoxo ético a partir de uma interessante reflexão ontológica: "Mas esses mundos concretamente individuais, irrepetíveis, de consciências que realmente agem (...) incluem momentos comuns -, não no sentido de conceitos universais ou leis, mas no sentido de momentos ou const ituintes comuns em suas várias arquitetônicas concretas."

Nos momentos comuns do conjunto de mundos concretamente individuais reside o que denominamos de (inter)subjetividade bakhtiniana. Esses momentos comuns, em suas várias arquitetônicas concretas, são a ponte ontológica da ética individual bakhiniana, ponte essa, que como veremos, será determinante na conformação ét ica de cada ser.

É essa arquitetônica concreta do mundo real do ato realizado que a filosofia moral tem de descrever, isto é, não o esquema abstrato mas o plano ou desenho concreto do mundo de uma ação ou ato unitário e único, os momentos básicos concretos de sua construção de sua mútua disposição. Esses momentos básicos são eu-para-mim, o outro-para-mim e eu-para-o-outro (BAKHTIN, 2016, p. 71).

Ou seja, o ato ético possui uma arquitetônica ontológica, já que o ato é de responsabilidade do ser, embora sua arquitetônica pressuponha que ele não seja propriedade de um ser, razão pela qual sua ética pode ser considerada ontologicamente intersubjet iva. Na ét ica bakht iniana o que está em jogo é a responsabilidade do ser com o próprio ser; por outro lado, em sua arquitetônica ontológica fica implícito que a alteridade constitui, de alguma maneira, essa responsabilidade. A ênfase de Bakhtin (2016), no aspecto concreto dessa arquitetônica do mundo, dá-se, justamente, para reforçar o pensamento de que ela não é uma abstração conceitual universal, uma média geral de relações individuais. Para ele, a realidade dos seres é uma realidade concreta, não objetiva (no sent ido bakht iniano, do objetivo como descrição simbólica de um acontecimento), uma realidade da vida vivida e, portanto, uma arquitetura que não pode ser concebida como um 
conceito teórico a priori: "Essa arquitetônica é tanto alguma coisa dada como alguma coisa a-ser-realizada, porque é a arquitetônica de um evento. Ela não é dada como uma arquitetônica encerrada e enrijecida, na qual eu estou colocado passivamente" (BAKHTIN, 2016, p. 92). Assim o filósofo (BAKHTIN, 2016) encerra sua reflexão ontológica, destacando que a arquitetura concreta não seria uma estrutura enrijecida capaz de anular a responsabilidade do ser por seu ato ético.

\subsection{A alteridade e a responsabilidade para o Dasein}

O risco de solipsismo não é tão evidente, na ontologia de Heidegger (2005), como na ética de Bakhtin (2016). Na obra Ser e Tempo, o filósofo alemão preconiza a existência ôntica dos entes e, dentre esses entes, de outros Daseins. No entanto, ao apresentar a relação ontológica do Dasein com o mundo, com as coisas ou com os outros, como modos de ser do próprio Dasein, poderia abrir-se espaço a uma interpretação solipsista de sua teoria. Nesse sentido, como veremos, a seguir, o outro, em Heidegger (2005), não se reduz ao impessoal, aparentando ser um possível constituinte ontológico do próprio Dasein. Assim sendo, a dimensão alteritária comporta uma importante reflexão ética na ontologia heideggeriana, como veremos a seguir.

\subsubsection{O mundo e as coisas para Heidegger}

A const ituição ontológica fundamental do ente, chamado Dasein, é o ser-no-mundo. O entendimento do fenômeno mundo, portanto, é fundamental para a compreensão das estruturas do ser do Dasein. Como já vimos, o ser, do Dasein, é a sua existência. Daí a concluirmos que o Dasein, fundamentalmente, existe no mundo. A conceituação de mundo, heideggeriana, constitui-se fundamentalmente a partir da negação da noção cartesiana de mundo. Enquanto para o racionalista francês, a extensão (extensio) é a substância do fenômeno mundo, para o filósofo alemão essa é apenas uma característica ôntica dos entes. A espacialidade dos entes intramundanos (as coisas, em outros termos) e do Dasein, não podem, portanto, serem explicadas ontologicamente pela extensio. O espaço é um momento estrutural do ser-no-mundo e dos entes intramundanos. Para Heidegger (2005), o espaço descobre-se como espacialidade pertencente ao próprio ente quando, por exemplo, uma coisa está fora de seu lugar. Aquele lugar, portanto, é, para Heidegger (2005), um 
momento estrutural do instrumento.

Diferentemente do espaço, o mundo, não é um constituinte comum dos instrumentos e do Dasein: "Mundo é um caráter da própria pre-sença [Dasein]" (HEIDEGGER, 2005, p. 105). Para Heidegger, o ser dos entes, na mundaniedade, explicaria a natureza e não o fenômeno do mundo. Entender o mundo é investigar o Dasein como serno-mundo em sua cotidianidade; já os seres simplesmente dados, por sua vez, seriam destituídos de mundo:

Um ente só poderá tocar um outro ente simplesmente dado dentro do mundo se, por sua natureza, tiver o modo de ser-em, se, com sua presença, já se lhe houver sido descoberto um mundo. Pois a partir do mundo o ente poderá, então, revelar-se no toque e, assim, tornar-se acessivel em seu ser simplesmente dado. Dois entes que se dão simplesmente dentro do mundo e que, além disso, são em si mesmos dest ituídos de mundo, nunca se podem 'tocar', nunca um deles pode 'ser e estar junto ao' outro (HEIDEGGER, 2005, p. 93).

O mundo como fenômeno exclusivamente humano reforça a crítica ao conceito cartesiano da extensão como substância, que explicaria a natureza ontológica do mundo. Portanto, mundano é um modo de ser específico do Dasein e o intramundano dos seres simplesmente dados. O ser-no-mundo é uma constituição necessária e a priori do Dasein, mas essa constituição não o determina completamente. De maneira semelhante vimos como a arquitetura do mundo concreto, para Bakhtin (2016), não suplanta a responsabilidade individual pelo ato do acontecimento do ser. $\mathrm{O}$ mundo é algo que o Dasein, como ente, sempre esteve. Mas somente na condição ontológica de ser-no-mundo, pode, o Dasein, tocar as coisas e tocar os outros. O mundo e as coisas, podem existir ônticamente independemente do Dasein. Já ontologicamente elas existem a partir das estruturas existenciais do Dasein.

\subsubsection{O impessoal e a alteridade em Heidegger}

O próprio, para Heidegger (2005), é o quem do Dasein. O ser-próprio, portanto, seria apenas um dos modos de ser do Dasein. Essa condição é chamada por ele de dissolução do 'eu'. Dentre as estruturas originárias do Dasein estão: o ser-no-mundo, o ser-com e co-presença. Podemos concluir que, antes de cada presença própria, os outros já estariam co-presentes no ser-no-mundo. De maneira muito semelhante, à noção de alteridade de Bakht in (2016), para Heidegger (2005), o ser-com-o-outro, determina existencialmente o Dasein: 
No ser-com e para os outros, subsiste, portanto, uma relação ontológica entre pre-senças. Essa relação, pode-se dizer, já é const itutiva de cada presença própria, que possui por si mesma uma compreensão do ser e, assim, relaciona-se com a pre-sença (HEIDEGGER, 2005, p. 174).

Podemos perceber que, para Heidegger (2005), a alteridade é um constituinte ontológico do Dasein. Assim sendo, na compreensão pré-ontológica de qualquer Dasein já subsiste uma compreensão dos outros, porque ser é ser-com. O ser-com, para ele, deve ser interpretado pelo fenômeno da cura [Sorge, também traduzido como cuidado]. A cura, para Heidegger (2005), determina o ser do Dasein em geral. Embora não possamos aprofundar essa questão, lembramos que a preocupação central do filósofo alemão é a interpretação do sentido geral do ser. Daí a concluirmos o local de destaque que a alteridade tem em sua reflexão ontológica. Interessante notar que, para Heidegger (2005), o ponto de contato inicial, entre os Daseins, não é a linguagem, mas as próprias ocupações manuais. Para ele, a co-pre-sença vem ao encontro a part ir do que está à mão no mundo. Isso não significa que, para ele, os outros devem ser recebidos como instrumentos pelo Dasein. Ao contrário, a noção de ocupção diz da relação do Dasein com os instrumentos, e a de preocupação diz da relação do Dasein com os outros (co-presença). Para Heidegger (2005), o que muitas vezes ocorre, na convivência cot idiana, é o rebaixamento da preocupção. Nesse rebaixamento os outros são tratados como instrumentos.

Vemos, portanto, que Heidegger (2005) não subestima a importância do outro na constituição do Dasein. Da mesma forma, quando ele estuda o fenômeno do impessoal ele não está negando a identidade individual, ou como ele denomina, o modo próprio do Dasein. Para ele, tanto o próprio, o outro e o impessoal são elementos constituintes do Dasein. O impessoal não é um sujeito universal nem transcendental, como o de Kant (apud BAKHTIN, 2016) em seu imperativo categórico. O próprio do Dasein cotidiano é o próprio impessoal, do ser que de-caiu na cotidianidade.

O impessoal desenvolve sua própria ditadura nesta falta de surpresa e de possibilidade de constatação. (...) O impessoal, que não é nada determinado mas que todos são, embora não como soma, prescreve o modo de ser da cotidianidade (HEIDEGGER, 2005, p. 179).

O impessoal, essa espécie de senso comum, é um constituinte do Dasein que estabelece uma relação ontológica contraditória em seu próprio ser na medida em que 
"prescreve todo julgamento e decisão, o impessoal retira a responsabilidade de cada presença" (HEIDEGGER, 2005, p. 180). O impessoal é o álibi para a ação do Dasein. Muitos tomam o impessoal como próprio e o fazem como parte da medianidade do mundo. Mas a ditadura do impessoal rebaixa a responsabilidade ét ica do Dasein e, como Heidegger (2005) analisa mais a frente, em Ser e Tempo, impede que se saia de uma compreensão préontológica para se avançar na interpretação do sent ido do ser. Do ponto de vista ét ico, para Heidegger (2005), a reação ao impessoal, ao de-caimento, no mundo, são condicionantes para que o Dasein avance em sua ontologia. Dessa maneira procuramos fechar o círculo que conecta a ética à ontologia em Bakhtin (2016) e a ontologia à ét ica em Heidegger (2005).

\section{Discurso e (inter)subjetividade}

Nos tópicos anteriores, vimos que a intersubjetividade é um fenômeno ontológico tanto para Bakht in (2016) quanto para Heidegger (2005). Enquanto para o filósofo russo trata-se da arquitetônica do mundo concreto do ato como momentos comuns dos acontecimentos do ser, para o alemão, o ser-com e a co-pre-sença são estruturas originárias do Dasein. A partir dessa configuração ontológica, para os dois pensadores, os seres já nascem com uma predisposição ontológica para a intersubjetividade. A intersubjetividade, para eles, portanto, seria um a priori necessário e inescapável? Como veremos, a seguir, para os dois filósofos, o exercício da possibilidade intersubjetiva é uma decisão ética do acontecimento do ser ou do Dasein.

\section{1 $O$ ato responsável e a intersubjetividade}

A possibilidade ontológica da intersubjetividade, em Bakhtin (2016), corresponde, como vimos, aos momentos principais de sua arquitetônica: o eu-para-mim, o eu-para-ooutro e o outro-para-mim. Mas somente o ato responsável, ao circunscrever a vida vivida junto ao seu conteúdo-significado pode ser o caminho à interconexão dos acontecimentos dos seres. O ato sem responsabilidade, seja ele teórico ou estético, separa-se da vida e torna-se um objeto abstrato que reflete teorias e expressões de outrem, mas não a vida de quem o executa. Se a teoria é insuficiente para expressar o vivido, que ato estaria em melhores condições de servir de caminho à intersubjet ividade? 
Seria um erro assumir que essa verdade concreta do evento que o realizador do ato vê e ouve e experimenta e compreende no ato único de uma ação responsável é alguma coisa inefável, isto é, que só possa ser vivamente experimentado de algum modo no momento de realizar o ato, mas não pode ser enunciado clara e distintamente. Eu penso que a linguagem está muito mais adaptada a enunciar precisamente essa verdade, e não o momento abstrato da lógica em sua pureza (BAKHTIN, 2016, p. 48-49).

$\mathrm{O}$ ato ético responsável não somente circunscreve a vida e seu significado. Ele também pode comunicar, a outros seres, essa verdade experimentada, em particular, em um de seus momentos. Como vimos, na citação acima, o momento abstrato da lógica é incapaz de fazer essa comunicação. Para Bakht in (2016), apenas a linguagem, como um ato ético e responsável, pode transformar a possibilidade ontológica da intersubjetividade em uma realidade concreta. É interessante notar que o termo russo postupok, traduzido como ato ético responsável, etimologicamente significa "um passo dado" ou "dar um passo" (LIAPUNOV, 2016); o ato ético responsável da linguagem é justamente o passo decisivo, para Bakhtin (2016), no caminho da intersubjetividade. Tomemos mais uma de suas reflexões, sobre a linguagem, nesta obra inicial, que indica de maneira muito vibrante o alvorecer de sua teoria linguíst ica:

A expressão, do interior, de um ato realizado, e a expressão do Ser-evento único e unitário no qual esse ato é realizado, requerem a inteira plenitude da palavra: seu aspecto de conteúdo (a palavra como conceito) tanto quanto seu aspecto palpável-expressivo (a palavra como imagem), e seu aspecto emocional-volitivo (a entonação da palavra) em sua unidade. (BAKHTIN, 2016, p. 49).

Aqui, Bakht in (2016) reforça a plenitude da palavra como um ato, para que ela seja capaz de expressar o vivido e o experimento pelo ser. Dentre esses aspectos, destaca-se a entonação da palavra, aspecto de grande relevância para a futura semânt ica bakht iniana e que encontra um relevante ponto de contato com o nosso filósofo de Copenhague: "Objetivamente, acentua-se: o que é dito; subjetivamente: como isso é dito." (KIERKEGAARD, 2013, p. 213).

\subsection{Discurso, falatório e intersubjetividade}

Como analisamos no ponto 3.2 , o que chamamos de intersubjetividade, para Heidegger (2005), é uma característica ontológica do Dasein. Nosso desafio, no presente 
ponto, é mostrar o papel da linguagem dentro dessa estrutura ontológica e, sobretudo, o significado ét ico dessa discussão em Ser e Tempo. Para Heidegger (2005), a reflexão acerca do discurso está intimamente ligada ao problema gnosiológico, do processo do conhecimento. Partindo da definição de גoyos (logos), em Aristóteles, Heidegger (2005) mostra-nos a incorreção de associar esse conceito à razão ou juízo. Para o filósofo alemão, o sentido original de גoyos é de um discurso que faz ver, capaz de demonstrar, por ter a estrutura formal da síntese. No entanto, Heidegger (2005) demonstra a limitação da antiga

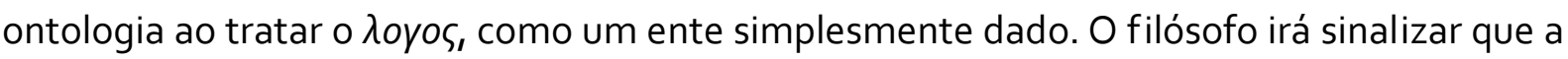
linguagem está radicada na constituição da abertura do Dasein e que o seu fundamento ontológico-existencial é o discurso. No discurso, o Dasein se pronuncia. Para ele (HEIDEGGER, 2005) o discurso está associado à disposição, compreensão, interpretação e proposição; sendo a proposição uma demonstração que determina algo através da comunicação: "A totalidade significativa da compreensibilidade vem à palavra. Das significações brotam palavras. As palavras, porém, não são coisas dotadas de significados" (HEIDEGGER, 2005, p. 219). Como vemos, Heidegger (2005) não trata o discurso como um ente, como faziam os gregos, mas como esses associa o $\lambda$ oүo e de demonstração.

Essa abordagem do discurso, difere um pouco da bakhtiniana que, ao menos em Para uma filosofia do ato, aborda a palavra mais em seu aspecto expressivo do que gnosiológico. Embora Heidegger (2005) não faça uma abordagem linguística, em Ser e Tempo, são muito interessantes as rápidas reflexões que ele faz sobre o fenômeno da comunicação humana. Por exemplo: "Sentido é um existencial da pre-sença e não uma propriedade colada sobre o ente (...)" (HEIDEGGER, 2005, p. 208) e "A escuta e o silêncio pertencem à linguagem discursiva como possibilidades intrínsecas" (HEIDEGGER, 2005, p. 220). São aspectos interessantes que se aproximam muito da Teoria Dialógica do Discurso que Bakht in desenvolveria anos mais tarde. Heidegger (2005) encerra o $\$ 34$, dedicado ao discurso e a linguagem do Dasein, com questionamentos importantes: "será a linguagem um instrumento à mão dentro do mundo? Terá ela o modo de ser da pre-sença?" Sem respondê-los, afirma a necessidade da elaboração da "estrutura do discurso como tal" (HEIDEGGER, 2005, p. 225). Essas são questões, dentre outras, que também serão abordardadas por Bakht in (2016), de forma inovadora, em sua teoria metalinguística.

Assim como Bakht in (2013), Heidegger (2005) também aborda a comunicação como 
um elemento expressivo. Daí podermos apontar que, para ele, a linguagem também pode ser considerada um caminho para o que denominamos intersubjet ividade:

Nela [na comunicação] se constitui a articulação da convivência que compreende. É ela que cumpre a 'partilha' da disposição comum e da compreensão do ser-com. Comunicação nunca é a transposição de vivências, por exemplo, de opiniões e desejos, do interior de um sujeito para o interior de outro sujeito. A co-pre-sença já se revelou essencialmente na disposição e compreensão comuns. O ser-com é partilhado 'explicitamente' no discurso. Isso significa: já é, só que ainda não partilhado porque não apreendido e apropriado (HEIDEGGER, 2005, p. 220-221).

Ou seja, para Heidegger (2005), na disposição e na compreensão, que são modos de ser do Dasein, a co-pre-sença já se revelou essencialmente. No entanto, o compartilhamento explícito das vivências dá-se no discurso. E é através do discurso que a intersubjet ividade deixa de ser uma possibilidade para tornar-se uma realidade apropriada. E, de modo semelhante ao filósofo russo, Heidegger (2005) destaca a escuta como elemento fundamental da alteridade: "A escuta é constitutiva do discurso. (...) Escutar é o estar aberto existencial da pre-sença enquanto ser-com os outros" (HEIDEGGER, 2005, p. 230).

Nesse ponto, iniciam-se as reflexões éticas de Heidegger (2005), relacionadas ao discurso, que assim questiona: o ser-no-mundo, em seu modo impessoal, possui um discurso e uma interpretação especiais? Para o filósofo alemão, o discurso do impessoal é o falatório. Esse é um discurso que nunca se comunica no modo de uma apropriação originária do ente. O discurso do Dasein, no modo impessoal, contenta-se em passar adiante a fala. Como o Dasein está lançado no mundo, o discurso traz a possibilidade de ser tornar falatório e, assim, manter o ser-no-mundo numa compreensão encoberta. O discurso transforma-se de abertura do ser-com em seu fechamento:

Obstruindo da maneira descrita, o falatório constitui o modo de ser da compreensão desarraigada da pre-sença. Ele não se apresenta como estado simplesmente dado de algo simplesmente dado mas existencialmente sem raízes, ele próprio é, no modo de um contínuo desenraizamento. Do ponto de vista ontológico, isso significa: como serno-mundo, a pre-sença que se mantém no falatório rasgou suas remissões ontológicas primordiais, originárias e legítimas com o mundo, com a copre-sença e com o próprio ser-em (HEIDEGGER, 2005, p. 230).

O Dasein, que se mantém no falatório, rasgou seus vínculos ontológicos primordiais, 
ou seja, rasgou sua relação ontológica com o mundo e com os outros. Nessas condições, as possibilidades ontológicas de intersubjetividade não se viabilizam e o Dasein relaciona-se com o impessoal: apenas escuta e repete o falatório. Como pode-se observar, aceitar o modo impessoal é uma responsabilidade do Dasein. Portanto, assim como para Bakhtin (2016), em Heidegger (2005) a intersubjetividade é uma possibilidade ontológica que só pode se viabilizar responsavelmente.

O ente que temos a tarefa de analisar somos nós mesmos. O ser deste ente é sempre e cada vez mais meu. Em seu ser, isto é, sendo, este ente se comporta com o seu ser. Como um ente deste ser, a pre-sença se entrega à responsabilidade de assumir seu próprio ser. O ser é o que neste ente está sempre em jogo (HEIDEGGER, 2005, p. 77).

\section{Considerações finais}

Como pudemos observar, ao longo de nossa exposição, o conceito bakhtiniano de mundo de fato vivido e a ex-sistência, como ser, do Dasein heideggeriano, são noções bastante produtivas para se pensar as relações interhumanas. Nessa perspectiva, para Bakht in (2016), o mundo não é uma realidade objet iva independente do ser: mundo e vida são realidades ontológicas que dão-se no ser e pelo ser. De forma semelhante, em Heidegger (2005), a ex-sistência, do Dasein, é o ser desse ente, de maneira que mundo, vida e alteridade existem como estruturas ou momentos ontológicos do ser-aí. Daí a propor e instaurar uma hermenêutica da facticidade, através da qual serão interpretadas as formas e as relações de co-ex-istencialidade do Dasein. Para ele (HEIDEGGER, 2005), a hermenêutica é fundamentalmente interpretação filosófica do sentido do ser; e a facticidade, condição factual do Dasein como ser-no-mundo. Assim sendo, a hermenêutica da facticidade possibilita a interpretação das formas e das relações de co-ex-istencialidade do Dasein. O ser-com-o-outro, portanto, para Heidegger (2005), parte da estruturação originária do Dasein.

Quanto às relações e às formas de alteridade que se inscrevem na arquitetônica concreta do mundo do ato realizado de Bakhtin (2016) através de um eu-para-mim, do outro-para-mim e do eu para o outro, procuramos demonstrar que os atos éticos, embora guardem uma responsabilidade individual extremamente radical, possuem momentos comuns. Esses momentos, em nossa perspectiva, correspondem à uma estrutura ontológica do acontecimento do ser, estrutura essa que é concreta e não um a priori 
abstrato. A noção de concreto, para Bakhtin (2005), não é a de objetividade, mas de não lógico-abstrato, já que a concretude dá-se no ser. Por conseguinte, o ato responsável, em Bakht in (2016) é também um ato ontológico.

Conclui-se que a (inter)subjetividade tanto para Bakhtin (2016) quanto para Heidegger (2005) existem como uma possibilidade ontológica que só pode se realizar concreta ou facticamente através da responsabilidade do ser/Dasein. Para ambos os pensadores a linguagem é, pois, uma via privilegiada de acesso à intersubjet ividade.

\section{Referências Bibliográficas}

BAKHTIN, M. M. Para uma filosofia do ato. Trad. Carlos Alberto Faraco e Cristóvão Tezza. Tradução para uso didático e acadêmico. Disponível em: http://docplayer.com.br/1362326Para-uma-filosofia-do-ato.html. Acessado: 28/08/2016.

BAJTIN, M. M. Hacia una filosofía del acto ético. De los borradores e otros escritos.Trad. Tat iana Bubnova. Barcelona: Anthropos, 1997.

BOCHAROV, S. G. Introdução à edição russa. In: Para uma filosofia do ato. Trad. Carlos Alberto Faraco e Cristóvão Tezza. Disponível em: http://docplayer.com.br/1362326-Parauma-filosofia-do-ato.html. Acessado: 28/08/2016.

DYNNIK, M. A. Historia de la filosofia. Org. DYNNIK, M.A. Trad. VAZQUEZ, Adolfo Sanchez. $2^{\text {a }}$ edição. Cidade do México: Editorial Grijalbo, 1968.

HEIDEGGER, M. Ser e Tempo. Trad. Márcia Sá Cavalcante Schuback. Petrópolis: Vozes, 2005.

HUSSERL, E. A crise das ciências europeias e a fenomenologia transcendental. Trad. Diogo Falcão Ferrer, $1^{\mathrm{a}}$. ed. Rio de Janeiro: Editora Foresense, 2012.

KIERKEGAARD, S. A. Pós-escrito às migalhas filosóficas. Vol.I.Trad. Álvaro Montenegro Valls e Marília Murta de Almeida. Petrópolis: Vozes, Bragança Paulista: São Francisco, 2013.

SAMPAIO, M. C. H. Caminhos do pensamento subjetivo para o tornar-se (inter)subjetivo: uma abordagem filosófica da linguagem. Desenredo, vol.12 (1), 2016, p. 201-216.

\footnotetext{
' Ricardo Lima Gomes, Graduando em Letras. Bolsista do Programa de Iniciação Científica UFPE/CNPq. rmineiro.pe@gmail.com

ii Maria Cristina Hennes Sampaio, Professora Doutora do Programa de Pós-Graduação em Letras da UFPE, Líder do GP/CNPq Linguagem, sociedade, saúde e trabalho.

mc.hennes@hotmail.com
} 